\title{
BMJ Open Utilisation of the principles of the Armed Forces Covenant in NHS Trusts and Clinical Commissioning Groups across England: a freedom of information investigation
}

Gill McGill, Gemma Wilson, Michael Hill, Matthew D Kiernan

To cite: McGill G, Wilson G, Hill $\mathrm{M}$, et al. Utilisation of the principles of the Armed Forces Covenant in NHS Trusts and Clinical Commissioning Groups across England: a freedom of information investigation. BMJ Open 2019;9:e022053. doi:10.1136/ bmjopen-2018-022053

- Prepublication history for this paper is available online. To view these files, please visit the journal online (http://dx.doi org/10.1136/bmjopen-2018022053).

Received 15 February 2018 Revised 25 October 2018 Accepted 26 0ctober 2018
Check for updates

(c) Author(s) (or their employer(s)) 2019. Re-use permitted under CC BY-NC. No commercial re-use. See rights and permissions. Published by BMJ.

Nursing, Midwifery and Health, Northumbria University, Newcastle upon Tyne, UK

Correspondence to Gill McGill;

gill.mcgill@northumbria.ac.uk

\section{ABSTRACT}

Objectives To determine the extent to which National Health Service (NHS) service providers appoint a named Armed Forces veteran lead or champion, and to explore the commissioning of veteran-specific services by Clinical Commissioning Groups.

Design A convergent mixed method design was used to improve understanding obtained from the information provided by respondents on their practice. The study comprised two parts: phase 1 involved NHS Trusts, and phase 2 involved Clinical Commissioning Groups.

Setting All NHS Trusts and Clinical Commissioning Groups in England were contacted using a freedom of information request.

Participants All NHS trusts and Clinical Commissioning Groups across England.

Interventions Initially, existing national websites were searched to gather information within the public domain. An audit was carried out, using the Freedom of Information Act (FOIA) 2000 to gather further information.

Primary and secondary outcome measures The FOIA 2000 applies to UK Government departments and public authorities, including NHS Trusts in England, Wales and Northern Ireland.

Results Responses from the freedom of information requests illustrate inconsistencies in relation to adopting the principles of the Armed Forces Covenant. The inconsistencies extend to the practice of appointing an Armed Forces Veteran Lead or an Armed Forces Veteran Champion. There is also evidence to suggest a lack of commitment to and understanding of policy guidance in relation to Clinical Commissioning Group responsibility for commissioning veteran-specific services.

Conclusions Findings from this study support the case for making improvements to, and improving the consistency of, commissioning practices for veterans.

\section{INTRODUCTION}

Since 2008 when the Ministry of Defence (MOD) and the National Health Service (NHS) funded the first veterans' mental health pilot services there has been an increasing concern about and focus on
Strengths and limitations of this study

- The freedom of information (FOI) request method allowed this study to capture a large amount of nationally representative data within time and financial resources available.

- Despite the legal obligation to reply to FOI requests, not all of the organisations contacted replied.

- Consistency of responses varied as the FOI request was inevitably open to subjective interpretation by the responders.

- Responses were included in this study only if the organisation replied within 20 working days.

- The evidence from this study provides scope for further discussion and an opportunity to build on the knowledge gained.

veterans' mental and related health needs. The MOD ${ }^{1}$ describe the Armed Forces Covenant as an agreement between the armed forces community, the nation and the government. Through employing the principles of the Armed Forces Covenant in practice, NHS Trusts have the opportunity to build their reputation as an Armed Forces friendly organisation. It is expected that treatment providers will have due regard to the Armed Forces Covenant and ensure equity of access to services for armed forces personnel and their families across England. ${ }^{2} 3$ This was given further emphasis and priority with the publication of the Murrison Report ${ }^{4}$ and the Armed Forces Covenant. ${ }^{5}$ The Armed Forces Covenant states:

Veterans receive their healthcare from the NHS, and should receive priority treatment where it relates to a condition which results from their service in the armed forces, subject to clinical need. Those injured in service, whether physically or mentally, should be cared for in 
a way, which reflects the nation's moral obligation to them, whilst respecting the individual's wishes. For those with concerns about their mental health, where symptoms may not present for some time after leaving service, they should be able to access services with health professionals who have an understanding of armed forces culture. ${ }^{5}$

NHS England is expected to ensure that services are commissioned to support consistent high standards across the country. NHS England are specifically responsible for promoting the NHS Constitution and delivering requirements of the Secretary of State's Mandate ${ }^{6}$ in line with the commitments made by the Government under the Armed Forces Covenant.

In practice, NHS providers are required to have a set of common access policies to ensure equity of access for service personnel and their families. NHS England expect providers to have due regard to the Armed Forces Covenant in managing their waiting lists and interprovider transfers. There is an expectation that priority treatment will be offered to veterans for service attributable conditions, subject to the clinical priorities of other patients. There is also an expectation that some bespoke services for veterans will be commissioned and that a national veterans' mental health service will be procured.

Mental health services for those leaving the armed forces and veterans now include a dedicated community based service, Mental Health Transition Intervention and Liaison Service (TiLS). ${ }^{7}$ This service provides treatment for early signs of mental health problems and access to therapeutic treatment for complex mental health difficulties/trauma. NHS England is responsible for the commissioning of TiLS. However, Clinical Commissioning Groups (CCGs) are responsible for the wider commissioning of mental health services in their area and, as part of this, need to understand and take into account the health needs of veterans and their families. It is expected that there will be close working between CCGs, local authorities and third sector organisations, through utilisation of the Armed Force Covenant and reflected in joint strategic health assessments. ${ }^{8}$

One of the significant initiatives implemented in England in 2015 was the specific inclusion of health commitments of the Armed Forces Covenant in the NHS Constitution and Mandates. In this regard, there is also an expectation that there will be co-ordination between NHS employers and all Trusts to nominate a Covenant Champion and point of advice and guidance across the Trusts. NHS England is also working with the clinical commissioners to further raise awareness. ${ }^{9}$ It is expected that bespoke services for veterans (such as mental health services) will be commissioned by CCG either individually or collectively. The CCG's responsibilities are to commission all secondary and community services required by Armed Forces' families (registered with NHS General Practitioner practices) and services for veterans. ${ }^{3}$ Therefore, this study had two main aims ${ }^{1}$ : to understand the extent to which NHS Trust appoint a named veteran lead or champion and ${ }^{2}$ to investigate the commissioning of veteran-specific services by CCG.

\section{METHODS \\ Design}

The study used a convergent mixed method design. The mixed method approach to the study was sequential in order to conduct the necessary degree of quantitative research, analyse the results and then build on the findings. ${ }^{10}$ This approach supports the aim to improve understanding rather than to measure or quantify what has been obtained from the information provided by respondents on their particular practice. ${ }^{11}$

The Freedom of Information Act (FOIA) 2000 applies to UK Government departments and public authorities, including NHS Trusts in England, Wales and Northern Ireland. A freedom of information (FOI) request survey methodology was chosen from two main reasons. First, the practical difficulties of discovering the required information from a search of each organisation's website or by securing access through negotiation with each organisation, and second, the advantages of a standardised request in facilitating a qualitative and quantitative comparison on the responses. To gather the data for the study itself, a standardised FOI request was created so that responses from separate NHS Trusts could be compared. This allowed for an acceptable level of validity as well as facilitating a level of replicability.

The study is based on the premise that appointing a named veteran lead or champion in NHS Trusts is a minimum indicator of commitment to the Armed Forces Covenant to provide, what the MOD describe a dedicated focus to implementation of the Covenant principles. ${ }^{1}$ Armed Forces Champions are a key factor in raising awareness of the covenant commitments and embedding them into the healthcare system.

\section{Study sample}

FOI email requests were sent to all NHS Trusts and CCGs in England. For NHS Trusts, the FOI request was organised into four subgroups consisting of: 59 Mental Health Trusts, 156 Acute Trusts, 19 Healthcare Trusts and 8 Ambulance Trusts. For CCGs, 209 were contacted. Before the FOI request was made, a thorough search of the existing national websites was made to determine if any of the information was already in the public domain.

\section{Data collection}

A survey method was employed to collect data using FOI requests. In order to obtain accurate information, the request was inclusive of all organisations identified as either having the ability to appoint a named veteran lead or having responsibility for commissioning services to meet the needs of veterans. The study was conducted in two phases to adequately support monitoring, analysis and reporting of the findings. This study was conducted 


\section{Box 1 Freedom of information request questions}

Phase 1:

- Do you have a lead/champion for Armed Forces veterans or military families? Please indicate Yes or No. If yes, can you provide contact details in a return email?

Phase 2:

- In your area, do you commission Armed Forces veteran-specific healthcare service(s)? If yes, can you please provide the service commission by the Clinical Commissioning Group (CCG) in your area? If no, can you tell us if veteran-specific healthcare provision for your area is part of your CCG commissioning intentions for the future?

in two phases as they were related to two questions, for two different organisations; the first targeted NHS trusts, and the second CCGs (box 1).

Based on the intent of the Armed Forces Covenant, we judged the minimum action by a trust which had signed up to appoint a named lead and the questions are based around this premise.

\section{Data sources}

Between 1 July and 31 October 2015, identical FOI requests were sent to 272 NHS Trusts in England. In addition, between October 2015 and January 2016, identical FOI requests were sent to all 209 CCGs in England.

\section{Patient involvement}

No patients were involved in setting the research question or the outcome measure, nor were they involved in developing plans for recruitment, design or implementation for the study. No patients were asked to advice on interpretation or writing up of the results. There are no plans to disseminate the results of the research to study participants or the relevant patient community.

\section{Analysis}

Separate analysis of the quantitative and qualitative data was carried out in parallel with the responses to the closed and open-ended survey question integrated in the FOI survey tool. This methodological approach was based on the method of data merging by Ross and Whittaker. ${ }^{12}$ Descriptive statistics were used to describe response,

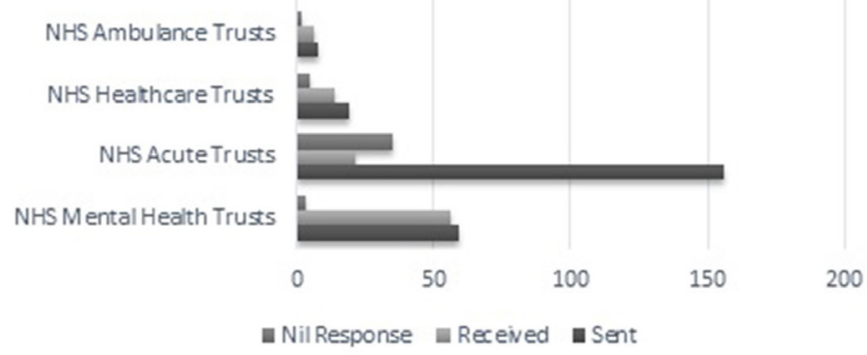

Figure 1 Comparative response rate of freedom of information request National Health Service (NHS) Trusts.

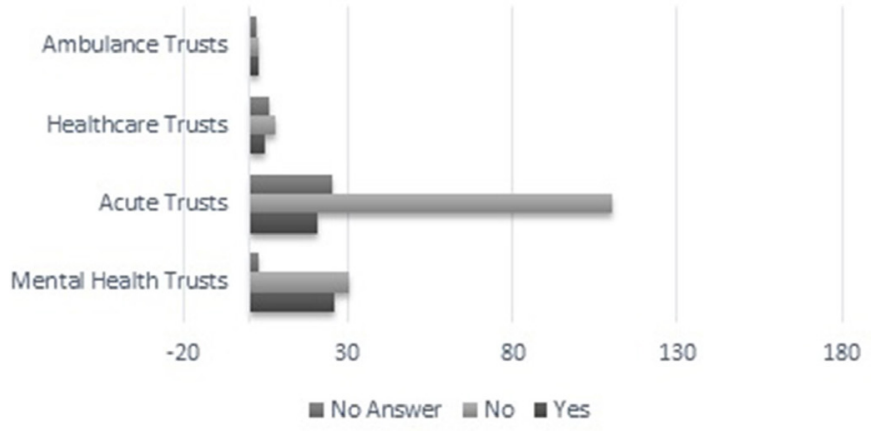

Figure 2 Comparative response to part 1 of the study - 'do you have a named veteran lead'-from all National Health Service Trusts.

engagement and distribution of responses, and content analysis was used for the textual data. In content analysis, responses are coded in order to identify and report patterns within the data. ${ }^{11} 13$ Patterns were identified based on representative responses from across the data.

\section{RESULTS}

The results are divided into two parts based on phase 1 and phase 2 of the study. The information provided in response to the survey covered a range of descriptions about the Armed Forces Covenant, the Joint Strategic Needs Assessment (JSNA) process and commissioning responsibility, as well as about the nature and extent of veteran-specific services. Of the 272 NHS Trusts and 209 CCGs that the FOI request was sent to, the response rate was $86 \% \quad(\mathrm{n}=236)$ and $74 \% \quad(\mathrm{n}=155)$, respectively. Although the FOIA imposes a statutory duty to respond to request for information within 20 working days, $13 \%$ of responding NHS Trusts $(\mathrm{n}=272)$ and $26 \%$ of responding CCGs ( $\mathrm{n}=209)$ did not meet this statutory requirement along with those that did not respond at all.

\section{Phase 1}

Figure 1 shows the response rate from all the NHS Trusts contacted. Of the 156 NHS Acute Trusts contacted, only 21 responded to this FOI request. Six of eight NHS Ambulance Trusts, 14 of 19 NHS Healthcare Trusts and 56 of 59 NHS Mental Health Trusts also responded.

Figure 2 reports whether the Trusts had appointed a veteran lead within their organisation. As with figure 1, the Mental Health and Ambulance Trusts had the highest response rate. However, little more than a third had appointed veteran leads $(36 \% \mathrm{n}=151)$.

Of the Trusts that did not have appointed leads, some provided additional information on future intentions:

Not yet but we have signed Armed Forces Covenant and intend to appoint a lead. (Respondent 143)

No lead - we refer to military services commissioned by ... CCG (Respondent 14)

In addition to the inconsistencies with appointing a veteran lead, it was evident that there was little consensus 


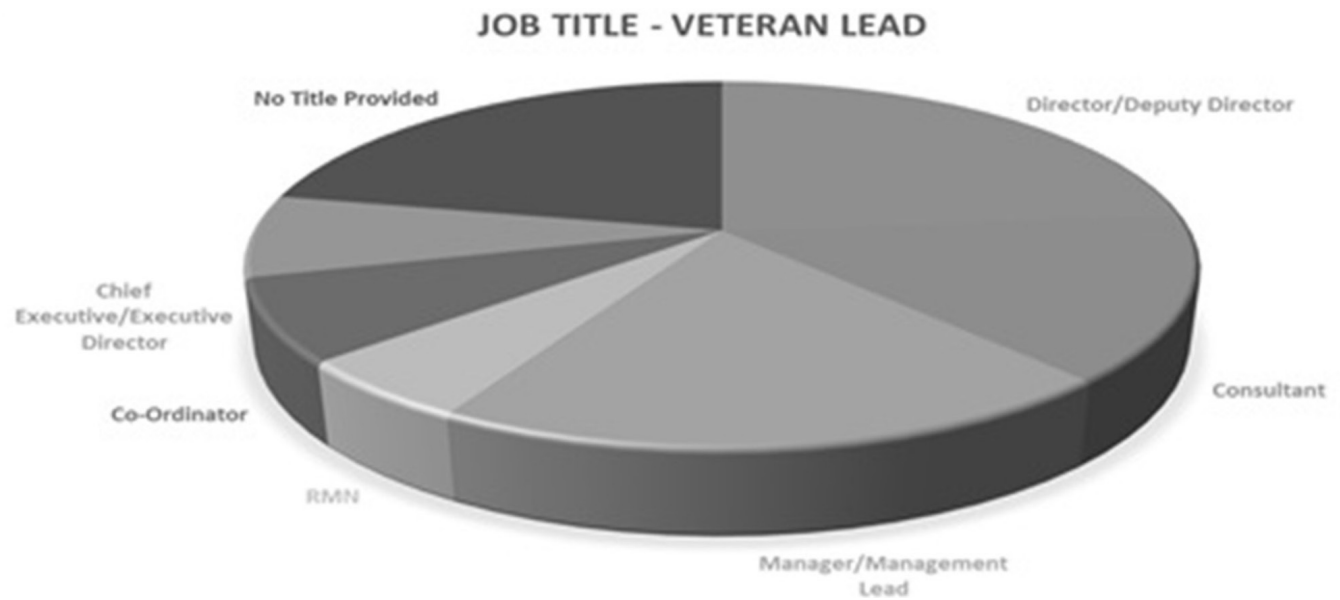

Figure 3 Job titles provided by National Health Service Trusts who confirmed a named veteran lead or champion. RMN, Registered Mental Health nurse.

as to who within an NHS Trust should be appointed into this role. Figure 3 demonstrates that appointment of a veteran lead is inconsistent across trusts, and who is appointed appears to be significantly random and inconsistent.

The majority of appointed leads were reported as being managers or management leads $(n=85 ; 23 \%)$ with a number described as directors or deputy directors in the Trusts $(\mathrm{n}=85 ; 18 \%)$. Others are described as chief executives, co-ordinators, consultants and a registered nurse. As such, it was difficult to extract from the data what the role undertaken by the named leads was, and how it related to the Armed Forces Covenant.

\section{Phase 2}

A significant finding within the phase 2 CCG data was the apparent confusion around veteran commissioning responsibilities. Of the 155 CCG responses, $22 \%(n=34)$ were redirected to NHS England with the respondents suggesting that the responsibility for commissioning veteran-specific services sat with that NHS organisation:

services for veterans are commissioned by NHS England and not at a local CCG level (Respondent 6)

CCG services are commissioned to meet the needs of their demographics including veterans, but they do not have specific veteran pathways. (Respondent 20)

When reflecting on future commissioning, 26\% $(\mathrm{n}=40)$ of CCG respondents reported that they had no future plans for commissioning veteran-specific services:

we are not considering in any forthcoming commissioning or service decision decisions. (Respondent 35)

...no specific intentions however CCG is committed to honouring the military covenant in full (Respondent

In contrast to those respondents that have commissioned veteran-specific services, $25 \%(\mathrm{n}=39)$ described collaborative arrangements with partners and stakeholders. Data demonstrate that they provide veteran-specific community-based services to secure CCG investment in improving services in secondary care. Where veteran-specific services were commissioned, they were generally mental health services (specialist/consultant led treatment), in partnership with NHS Foundations Trusts. Respondents also described Improving Access to Psychological Therapies (IAPT) as a service available to veterans, provided within the NHS trust and aligned to CCG geographical areas. Although these services were not specifically aimed at veterans, they were aimed at offering National Institution for Health and Care Excellence-approved psychological therapies to individuals who experience common mental health problems.

veterans and reservists are a particular cohort of the population which IAPT aims to support, given the relatively high incidence of mental health problems experience by this part of the local population (Respondent 31).

In addition, service provision is described by one 'cluster' of CCGs as being commissioned within a complex arrangement attached to one commissioning support unit and mapped according to the respective geographical areas. For example, in one geographical area, there is a total of 25 CCGs attached to one commissioning unit with a 'host' commissioning lead for a veteran-specific service covering a number of areas in one particular region.

\section{DISCUSSION}

This study demonstrates the inconsistencies in NHS trusts and CCGs relating to the Armed Forces Covenant. Inconsistencies arose in the response to the FOI request, the appointment of a veteran lead, the job roles of the veteran lead and the commissioning of veteran-specific services. In response to the Defence Committee Armed Forces Covenant Report, ${ }^{14}$ the Government expressed disappointment that 10 years after the policy of priority access to healthcare for veterans, professional awareness 
and implementation remain inadequate. This rapid survey appears to evidence the lack of veteran leads and veteran-commissioned services across healthcare services in the UK.

Health Education England (HEE) promote the benefits of employing a veteran champion and discuss how they help to raise awareness about the issues faced by the armed forces community, veterans and their families. HEE described the veteran champion role as central to ensuring that government policies are considered appropriately so that veterans' rights are protected. In practice, veterans' champions will ensure the organisation is aware of, and follows, the Armed Forces Covenant which ensures that veterans and their families are not disadvantaged in their treatment. At best, veteran champions are arguably invaluable in raising awareness of the Armed Forces Covenant and essential when embedding the principles into a healthcare organisation. ${ }^{9}$ However, the findings of this study demonstrate that dedicated veteran leads/ champions have not been adopted by many NHS trusts in England. The Murrison Report ${ }^{4}$ identified the appointment of a veteran champion as one of the key themes that emerged as a critical success factor that should be taken into consideration by NHS Trusts in England. ${ }^{7}$ Some local NHS trusts have adopted this practice, such as NHS South Central have appointed local veterans champions across their NHS trusts, including GP champions to provide single points of contact. In addition, Tees, Esk and Wear Valley NHS Foundation trust have a network of veteran champions who represent the mental health teams from within the Trust. In terms of resource implications, there is potentially a pool of existing clinicians who are veterans, or family members of veterans working in the NHS and who may be willing to act as champions.

An additional and unexpected finding was the relatively poor response to FOI requests, notwithstanding FOI legislation. This is not an unknown phenomenon, and Bourke $e t a l^{15}$ highlight similar issues of poor response to FOI requests. However, these authors do maintain that the benefits of using FOI request in research still outweigh this potential challenge.

The findings from this study have provided an insight into the variable levels of commitment towards appointing named veterans leads within NHS Trusts. More importantly, some limited insights into how the Armed Forces Covenant is applied in practice is provided: this includes inconsistencies between the job roles of individual veteran leads. Variable levels of commitment is at odds with the recommendations of the Veterans' Transition Review ${ }^{16}$ which advocated for a network or Armed Forces Champions in order to ensure that armed service leavers have as much information as possible about health and other services. Where there was evidence of the Veteran Champion role existing, it was not clear as to whether this was viewed (organisationally) as an obligation or that there is a distinct role profile clearly outlining the duties involved. Responses from the NHS Trusts indicate that there are few veteran leads or veteran champions employed and, where this role is allocated, there is no evidence of a consistent approach or of a thoughtful process to appoint a champion. Similar concern is also outlined in the Armed Forces Covenant Annual Report, ${ }^{9}$ where the lack of progress made to identify armed forces champions, linked to CCG priorities and general practice, is discussed. We would suggest that those responsible for overarching policy developments in this area might wish to give additional consideration to the appropriate role profile for a veteran lead in NHS settings.

CCGs are the 'responsible commissioners' for veteran services and are key to setting fundamental objectives for commissioning. These objectives are ostensibly based on assessing the nature of health challenges for veterans and deciding how best to respond. JSNAs are accepted as an essential element in assessing local need, yet there is no evidence of a consensus of approach in relation to veterans' needs and future commissioning arrangements. ${ }^{3}$ JSNAs aim to improve community health and well-being and reduce inequalities for all ages. ${ }^{17}$ This study has highlighted some significant gaps in the extent to which the needs of veterans are included in future commissioning plans. The findings also highlighted inconsistencies in CCG approaches to service provision for veterans and commissioning intentions for the future in this regard.

NHS England ${ }^{3}$ asserts the aspiration to develop services for veterans that are designed for their particular needs. This includes services that are accessible and offer the 'right' care and support regardless of when people leave the armed forces. Despite this claim, 23\% of the CCGs who responded to the FOI request, stated that it is not their intention to commission veteran-specific services in the future. A smaller number of the respondents to the study described offering innovative services describing, for example, a 'one-stop shop' approach, while others described have a single member of a team covering a large area. Despite the clear guidance and policy directives, the responses from the CCG to the study highlight that there appears to be a significant level of misunderstanding or misinterpretation of commissioning responsibilities in relation to providing effective veteran-specific care and support.

There was a prevalent discourse throughout this study that maintained that it was/is the responsibility of NHS England for the commissioning veteran-specific healthcare. This claim arose repeatedly within the data analysis phase of the study. However, in contrast, current NHS guidance states that bespoke services for veterans, such as mental health services, should be the proper responsibility of CCG. Furthermore, there is an aspiration to make such commissioning practices intelligence-led, developed in partnership with the local authority and other local key stakeholders. The overarching intention is therefore for those commissioning health and social care services to do so on the basis of an accurate picture of local needs. Considering the Armed Forces as part of a JSNA should be used as a way of meeting the Community Covenant commitments. Being able to understand the unique 
circumstances faced by the Armed Forces community is vital for front-facing staff. ${ }^{1}$

The evidence from this study provides scope for further discussion and an opportunity to build on the knowledge gained, in order to identify instances of good practice. Findings from this study support the case for making improvements to, and improving the consistency of, commissioning practices for veterans. In line with recommendations made, NHS Trusts and CCG need to ensure services available to veterans are supported by a named veteran lead who is a trained member of staff and who understands the culture of the Armed Forces. ${ }^{2}$ The current fragmentation of commissioning arrangements and 'ad hoc' arrangements between localities across England (in their current form) would appear to be unsustainable. We would therefore advocate both (a) the maximisation of veterans' health needs assessment based on currently available data for each locale, and (b) a commitment to employing locally knowledgeable veterans' leads. These two measures alone would perhaps help take the Armed Forces Covenant beyond the level of a rhetorical assurance that 'something is being done' and transform this laudable commitment into a practical reality. Collectively, these measures would appear to underpin the instances of best practice collaborative commissioning identified in this study.

Contributors GMcG carried out a literature review and data collection. GMcG wrote the first draft of the article. GW and MDK contributed towards writing of the subsequent versions of the article and editing the final manuscript. MH supervised the overall project and editing of the final manuscript.

Funding The authors have not declared a specific grant for this research from any funding agency in the public, commercial or not-for-profit sectors.

Competing interests None declared.

Patient consent Not required.

Provenance and peer review Not commissioned; externally peer reviewed.

Data sharing statement Information gained through FOI Act is publicly available.

Open access This is an open access article distributed in accordance with the Creative Commons Attribution Non Commercial (CC BY-NC 4.0) license, which permits others to distribute, remix, adapt, build upon this work non-commercially, and license their derivative works on different terms, provided the original work is properly cited, appropriate credit is given, any changes made indicated, and the use is non-commercial. See: http://creativecommons.org/licenses/by-nc/4.0/.

\section{REFERENCES}

1. Ministry of Defence. Armed Forces Covenant. London: Ministry of Defence UK, 2016.

2. Forces in Mind Trust and Community Innovations Enterprise. Call to Mind: A frameowrk to action. London: Community Innovations Enterprise, 2015.

3. NHS England. Armed Forces and their Families Commissioning Intentions 2017/18 to 2018/19. Quarry Hill, England: NHS England, 2016.

4. Murrison A. Mo D, ed. Fighting fit: A mental health plan for servicemen and veterans. London: Minstry of Defence, 2010.

5. Ministry of Defence. Armed Forces Covenant interim report. London: Ministry of Defence, 2011.

6. Department of HealthDepartment of Health. The Mandate: $A$ mandate from the Government to NHS England: April 2014 to March 2015London: Department of Health, 2015.

7. NHS England. Next steps on the NHS Five Year Forward View: 17,500 forces veterans and service personnel to benefit from $£ 9 \mathrm{~m}$ investment in new and improved NHS mental health services, 2017. https://www.england.nhs.uk/2017/04/next-steps-on-the-nhs-fiveyear-forward-view-veterans/.

8. Forces in Mind Trust and NHS England. Call to Mind: Findings from the review of veterans and family members mental and related health needs assessments. London: Forces in Mind Trust, 2015.

9. Ministry of Defence UK. Armed Forces Covenant annual report 2016. London: Ministry of Defence, 2016.

10. Sumser J. A guide to Empirical Research in Communication. London: SAGE Publications Inc, 2001.

11. Creswell JW, Creswell JD. Research design: Qualitative, quantitative, and mixed methods approaches: Sage publications, 2017.

12. Ross J, Whittaker P. Freedom of Information: Is Openness Too Expensive, Too Difficult or Too Dangerous? Journal of Finance and Management in Public Services 2009;7:53-70.

13. McLaughlin H. Understanding social work research: Sage, 2011.

14. House of Commons Defence Committee. Armed Forces Covenant Annual Report 2016; Ninth Report of the Session 2016-2017. London: House of Commons Defence Committee, 2017.

15. Bourke G, Worthy B, Hazell R. Making freedom of information requests: a guide for academic researchers. London: The Constitution Unit, University College London, 2012.

16. Ashcroft M. The veterans' transition review: Biteback Publishing, 2014.

17. Department of Health. Statutory Guidance on Joint Strategic Needs Assessments and Joint Health And WellBeing Strategies. London: Department of Health, 2013. 
Correction: Utilisation of the principles of the Armed Forces

Covenant in NHS Trusts and Clinical Commissioning Groups

across England: a freedom of information investigation

McGill G, Wilson G, Hill M, et al. Utilisation of the principles of the Armed Forces Covenant in NHS Trusts and Clinical Commissioning Groups across England: a freedom of information investigation. BMJ Open 2019;9:e022053. doi: 10.1136/ bmjopen-2018-022053.

The previous version of this manuscript contains an error in 'Data sources' section figure as well as 'Results' section percentage rates. It should appear as:

\section{Data sources}

Between 1 July and 31 October 2015, identical FOI requests were sent to 242 NHS Trusts in England. In addition, between October 2015 and January 2016, identical FOI requests were sent to all 209 CCGs in England.

\section{RESULTS}

The results are divided into two parts based on Phase One and Phase Two of the study. The information provided in response to the survey covered a range of descriptions about the Armed Forces Covenant, the Joint Strategic Needs Assessment process and commissioning responsibility, as well as about the nature and extent of veteran specific services. Of the 242 NHS Trusts and 209 CCGs that the FOI request was sent to, the response rate was $40 \%(n=97)$ and $74 \%(n=155)$ respectively. Although the FOIA imposes a statutory duty to respond to request for information within 20 working days, $13 \%(n=31)$ of responding NHS Trusts and 34\% ( $n=54)$ of responding CCGs did not meet this statutory requirement along with those that did not respond at all.

\section{Phase 1}

Figure 1 shows the response rate from all the NHS Trusts contacted. Of the 156 NHS acute trusts contacted, only 21 responded to this FOI request. Six of eight NHS ambulance trusts, 14 of 19 NHS healthcare trusts and 56 of 59 NHS mental health trusts also responded.

Figure 2 reports whether the Trusts had appointed a veteran lead within their organisation. As with Figure 1, the mental health and ambulance trusts had the highest response rate. Just over half of all responses $56.7 \%(n=55)$ had appointed veteran leads.

Instead of

\section{Data sources}

Between 1 July and 31 October 2015, identical FOI requests were sent to 272 NHS Trusts in England. In addition, between October 2015 and January 2016, identical FOI requests were sent to all 209 CCGs in England.

\section{RESULTS}

The results are divided into two parts based on phase 1 and phase 2 of the study. The information provided in response to the survey covered a range of descriptions about the Armed Forces Covenant, the Joint Strategic Needs Assessment (JSNA) process and commissioning responsibility, as well as about the nature and extent of veteran-specific services. Of the 272 NHS Trusts and 209 CCGs that the FOI request was sent to, the response rate was $86 \%(\mathrm{n}=236)$ and $74 \%(\mathrm{n}=155)$, respectively. Although the FOIA imposes a statutory duty to respond to request for information within 20 working days, $13 \%$ of responding NHS Trusts $(n=272)$ and $26 \%$ of responding CCGs $(n=209)$ did not meet this statutory requirement along with those that did not respond at all. 
Phase 1

Figure 1 shows the response rate from all the NHS Trusts contacted. Of the 156 NHS Acute Trusts contacted, only 21 responded to this FOI request. Six of eight NHS Ambulance Trusts, 14 of 19 NHS Healthcare Trusts and 56 of 59 NHS Mental Health Trusts also responded.

Figure 2 reports whether the Trusts had appointed a veteran lead within their organisation. As with figure 1, the Mental Health and Ambulance Trusts had the highest response rate. However, little more than a third had appointed veteran leads (36\% $\mathrm{n}=151)$.

Open access This is an open access article distributed in accordance with the Creative Commons Attribution Non Commercial (CC BY-NC 4.0) license, which permits others to distribute, remix, adapt, build upon this work non-commercially, and license their derivative works on different terms, provided the original work is properly cited, appropriate credit is given, any changes made indicated, and the use is non-commercial. See: http://creativecommons.org/licenses/by-nc/4.0/.

(c) Author(s) (or their employer(s)) 2019. Re-use permitted under CC BY-NC. No commercial re-use. See rights and permissions. Published by BMJ.

BMJ Open 2019;9:e022053corr1. doi:10.1136/bmjopen-2018-022053corr1

A) Check for updates 